\title{
Pedagogical Grammar: Learners' Beliefs Do Matter
}

\author{
Mohammed Almazloum \\ University of Western Ontario \\ Canada
}

\begin{abstract}
Second language (L2) learners' beliefs about pedagogical grammar were relatively neglected. This study aimed to explore learners' beliefs about learning grammar in an English for Academic Purposes (EAP) program. The study conducted questionnaires and interviews to gain meaningful insights about eightL2 learners' beliefs. Learners' written essays were used to identify grammar mistakes and challenges. The findings indicated that the participants constructed their own perceptions about pedagogical grammar during the EAP program. The inclusiveness of grammar and its instruction to L2 learning were central to the learners' understanding of grammar. The learners recommended that teachers make balance between explicit and implicit teaching of grammar and the employment of their first language (L1) and L2 language. Integrity of corrective feedback, exposure to L2 inputs, and practice ofL2 grammar were suggested by the learners to contribute to their learning.
\end{abstract}

Keywords: pedagogical grammar; corrective feedback; discourse; explicit/implicit teaching

\section{Introduction}

Pedagogical grammar can be viewed as the version of grammar that seeks to find, frame, and describe criteria for language education and rules of language use. It helps to identify optimal ways for teaching and learning L2 language in a classroom (Ellis, 2006, Westney, 1994). L2 pedagogical grammar is an area of controversy (Ellis 2002) because grammar has footings in the linguistic theory, the learning psychology and language pedagogy. Entrenched in the complexity of the human mind and language, the intricacy of the biological, psychological, and socio-cultural subtleties underpinning language acquisition, use, and education, many questions pertaining to L2 pedagogical grammar have rather remain issues of theoretical and philosophical contestations. According to Scott Thornbury (1999, p. 14), "the history of language teaching is essentially the history of the claims and counterclaims for and against the teaching of grammar". Similarly, articulating the difficulty and the flux about grammar and lack of consensus about its instruction in classroom context, Hudson (1998, p. 4) asks, "is grammar teachable"?

Ample research on pedagogical grammar has addressed three major questions: (a) what is the nature of language grammar?, (b) what theoretical paradigms can offer a satisfactory account for the acquisition of grammar? ,i.e., "what pedagogical rules represent, in linguistic and psychological terms, how such rules relate to acquisition and how they are perceived by their users" (Westney, 1994, p. 72), and (c) what optimal methods can be taken in order to teach grammar to language learners? The three questions which pedagogical grammar research seeks to answer, are still a matter of controversy (Ellis, 2002).Thus, considering the controversy about pedagogical grammar, the centrality of learners to, albeit the paucity of research on their opinion concerning, grammar pedagogy, the study attempted to explore the following questions from the learners' perspectives and based on their L2 learning experiences and beliefs about learning grammar:

1- What is grammar from the perspective of L2 learners?

2- What are the L2 learners' perceptions about the importance of learning grammar?

3- What teaching and learning strategies do L2 learners advocate be employed to optimally promote their learning experience with grammar and L2?

\section{Literature Review}

\section{Grammar Pedagogy Controversy}

One major contention about grammar pedagogy is a definitional issue that stems from the linguistic theory. The notion 'grammar' has been varyingly and controversially defined (Hartwell, 1985). 
Francis (1954) distinguished three grammar paradigms: Grammar 1, "the set of formal patterns in which the words of a language are arranged in order to convey larger meanings", Grammar 2, "the branch of linguistic science which is concerned with the description, analysis, and formulization of formal language patterns", and Grammar 3, "linguistic etiquette" (p. 299-300). Another controversial issue about grammar teaching resides in the psychology of learning or the acquisition mechanisms. What theoretical paradigm may account for the underpinnings of the learning process, and inform an optimal teaching practice? In the 1960s, Chomsky suggested the Universal Grammar (UG) formal model of language acquisition. Language for Chomsky is grammar, inborn knowledge in the mind, i.e., an innate, universal faculty. Thus, Chomsky highlights grammar, but debunks the role of input; hence, the function and teaching of grammar. Although Chomsky's UG is meant to explicate the mechanisms underpinning L1 acquisition, his model has been widely adopted by second language acquisition (SLA) researchers (Clahsen \& Muysken, 1986; Schachter 1988; Hawkins, 2002), who seem to focus on learning not teaching grammar. With the advent of the sociolinguistics enterprise in the late 1960s and systemic linguistics (Halliday, 1973), the role of grammar teaching was downplayed (Male, 2011), due to the vogue of the communicative approach to language under the newly growing fields.

Unlike Chomsky, Krashen (1981) proposes an input-based model, yet (like Chomsky) highlighted learning rather than teaching grammar. Bresnan (1982) proposes the lexical-functional model to grammar that balanced form and function, stressed their indispensability, and emphasized that grammar input should be interactional. Thus, the theoretical controversy about grammar learning eventuated in a methodological contention about its instruction. The controversy centered on what teaching practices are optimal for grammar presentation; is it an implicit vs. an explicit approach to grammar teaching and a formal vs. a functional approach to grammar teaching? Correction has also been debated in grammar instruction.

\section{The Neglected Factor}

Debate reconciliation about grammar pedagogy is a way that helps to understand how learners perceive the practice. Learners' perception is essential because "the point of education is to accelerate the language acquisition process" (Larsen-Freeman, 2009, p. 78), and, effective teaching is an arrangement to successful learning. Citing Tomlison, Male (2011, p. 58) restates that in order to "succeed an EFL teaching, the students' expectations, needs and wants, attitudes and learning styles should be considered". Learners' beliefs are said to form a structured set of principles and are derived from teachers' and learners' prior experiences, school practices, and ones' individual personalities. Furthermore, what teachers do in the classroom is said to be governed by what they believe. These beliefs often serve to act as a filter through which instructional judgments and decisions are made. Moreover, there has been emphasis that attention to learners' individual beliefs and own capacity should be more than mere abstract universal theories of learning (Bernat, 2008). Some pedagogical beliefs are proposed to be developed along with three systematic educational dimensions: planning, implementation, and evaluation. These dimensions should maintain consistency to promote the quality of education. The justification for this vision occurs as a result to close examining of reality where there is a gap between theory and practice. More specifically, there is a gap between 'what should exist' and 'what does exist' as one of the central problems of an ESL program (Nunan, 1988).

InL2 context, considerable amount of research (Yang, 1992; Mori, 1999; Schulz, 2001; Davis, 2003; Kalaja \& Barcelos 2003; Loewen, Thompson, Nakatsukasa, Ahn, \& Chen, 2009; Male, 2011; Incecay \& Dollar, 2011) revealed correlation between learners' beliefs and their learning behaviors, styles, and linguistic achievement. At the behavior level, Yang (1992) found a strong correlation between learners' beliefs and anxiety. However, learner's beliefs on L2 grammar pedagogy have been "neglected" (Incecay \& Dollar, 2011, p. 3394). On the one hand, "studies that do look at students' beliefs typically focus on language learning in general and not on the role of grammar instruction in particular" (Male, 2011, p. 60). On the other hand, the existent studies that focused on the learners' beliefs concerning grammar teaching reported overlapping and controversial findings. These findings could be attributed to the instability about the construct of grammar and to the nature of beliefs as personal construal to the world.

It is essential to seek alternatives that may inform methods of identifying teaching grammar. One logical proposal rests on consulting learners as teaching is an alignment of learning and a response to learners' needs, assumptions, learning styles, expectations, and potentials. Starting from this position, I explored the learners 'experiences and beliefs about learning L2 grammar. Adding further argument to the already contested ones is not within the scope of this paper. 
Rather, it is an attempt to gain meaningful insights on how to relevantly define grammar with relation to learners' everyday practices and experiences with learning and to identify useful strategies to teach it more meaningfully.

\section{Academic Context}

This study is a mini project carried out in partial fulfillment of a larger scale project that aimed to reflect on the learners' experience with the EAP program at the target university. The findings of the project will help to draw appropriate recommendations obtained qualitatively from the learners whose voices should be heard by the leadership of the program. Such experience would be essential to decide future pedagogy and policy pursuing feedback about the learners' needs, wants, challenges, learning styles and preference, and prior knowledge.

\section{Methods}

The study used the qualitative research approach that informed the techniques of data collection and analysis to answer the research questions of the study. Achieving the purpose of the study as to explore L2 learners' beliefs and experience and answering the research questions gave rise to the methodological considerations explained below. In this regard, maintain that "the understanding or meaning of phenomenon, formed through participants and their subjective views, make up these worldviews. When participants provide their understandings, they speak from meanings shaped by social interaction with others and from their own personal histories" (Creswell\& Clark, 2011, p. 40). Asking focused questions in casual dialogic settings was central to obtaining the participants' perceptions. I employed an interpretational analysis to "find constructs... that can be used to describe and explain the phenomenon being studied" (Gall, Gall \& Borg, 2007, p. 466). I explored the beliefs and experiences of L2 learners with learning English grammar and how their beliefs may affect future endeavors to facilitate L2 learning experience.

\section{Participants}

The study sample consisted of a group of eight undergraduate students enrolled in undergraduate courses at a university in Ottawa, Canada, but in the same time were studying EAP. After obtaining an ethical clearance from IRB and the EAP department, an oral announcement by the researcher, who was not the instructor, was made in the L2 classroom where the student studied, inviting volunteering students to participate in the study. Five male and three female students volunteered to participate in the study. The participants were given a consent form that informed them about the nature of their participation and that they could withdraw from the study at any time without any consequences. After reading the consent form, they signed it. The age ranged between 19 and 21 . All the participants were non-native speakers of English who came from four different linguistic and cultural backgrounds. The participants had similar previous learning experiences in their home countries with approximately similar English language proficiency as they were enrolled in the same level and class. They came to Canada as students to complete an undergraduate degree. To keep their identities confidential, I gave the participants the following pseudonyms: John, Ali, Adam, Salem, Rayan, Young, Marry, and Cheng.

\section{Data Collection}

The data were collected interdependently, using three research instruments: semi-structured interviews, openended questionnaires, and essays written by the students. The semi-structured interviews and the questionnaires provided diversity of data about the participants, their experience with English before and after arrival in Canada, their view to language and grammar, and the reason why they joined the EAP program. Each student was asked to write an IELTS task 2 writing essay. The researcher provided written corrective feedback and asked the students to edit their essays in accordance with the feedback. Another round of corrective feedback was provided on the second draft and the students were asked to edit.

\section{Data Analysis}

I used an inductive coding approach informed by Saldana's (2009) guidelines to analyze data from the interviews and questionnaires. The coding process was data-driven in which it involved identifying codes and subthemes out of the participants' experiences which were essential in L2 learning contexts. The interviews were transcribed. The students' responses from the questionnaires were collected. I pre-coded the raw data by underlining the participants' quotes, comments and responses to derive descriptive codes (the wording the students used to describe the grammatical points they commented on). Descriptive codes were transposed into categories and subthemes. Data analysis also involved making meaningful connections among the categories and subthemes to help answer the research questions. Analyzing the students' essays helped me identify areas of grammar mistakes and challenges that faced the students during their learning. 


\section{Results and Discussions}

This section is devoted to summarize, describe, interpret, and discuss the major findings of the study, supporting these findings with the participants' anecdotes from the interview and the questionnaire, alongside with the evaluation of their writings. The findings of the study are centered on the three major research questions.

\section{Research question 1: "What is grammar from the perspective of L2 learners?"}

In response to the first question, "what is grammar from the perspective of L2 learners?", the participants provided four insights, suggesting that the view to grammar is situated in the learning context. In other words, they meant that the context of use informs the view of grammar. Firstly, grammar is syntactical or formal which speaks to their back-home experience with grammar. Secondly, grammar is formal-functional in which it maps onto an interactional or use-based understanding and speaks to the participants' experience with English in Canada. Thirdly, grammar is a rhetorical tool related to institutional requirements and experience with university education. Fourthly, grammar is the system of language in both its spoken and written forms. This represents the eventual conception of grammar by a 'sojourner' who receive education in an English-medium university (a combination of both the second and third meanings of grammar).

\section{Grammar as Syntax}

The first view to grammar is syntactically-oriented and was the initial perception to the construct developed by the participants in their L1 context which represents the traditional view to grammar. The participants recognized grammar as "sentence structure". For example, Salem described grammar as "the system you use to put words together and make correct sentences". Like Salem, Young considered grammar as an effective way to "connect different parts of speech to make an accurate sentence". This perception of pedagogical grammar represents the primitive view to 'school grammar' which Francis (1954) referred to as Grammar 2, "the branch of linguistic science which is concerned with the description, analysis, and formulization of formal language patterns" (p. 299). In this regard, it would be significant to postulate why the students view grammar as 'sentence structure'. The findings suggest that this view hinges on the way the students studied and experienced grammar within L2 learning back in their countries.

The students maintained that English back-home was treated as "any other school subject" such as history, geography, or philosophy. Ali elaborated on the way they studied grammar in their home country, "we studied English like any other subject. We memorized the rules and followed them when we wanted to write or speak. We found it difficult to speak outside the class". In other words, their knowledge concerning grammar was merely theoretical and descriptive, hence was divorced from application in actual language use. This ended them up in learning about English rather than learning the language itself using its grammar. This view could be informed by what Harris, Santangelo \& Graham (2010) identify as 'declarative knowledge' when learners are likely to learn through formal instruction in a certain context or through self-study.

Furthermore, as a school subject, the focus was on the exam; grammar was memorized but not acquired. The participants affirmed that they used to study for exams to pas and to get good marks. Cheng, for example mentioned that she used to "memorize the structures for the exam" then would either fail to "use" or "forget these structures" a day or two days after the exam. Adam also posited that they were prompted to pay more attention to the grammatical rules as they were an essential part of the exam, "our teachers always asked us to remember the rules and never forget them because they will appear in the exam". The students' comments on their past experience with grammar pedagogy is aligned with the distinction that Krashen (1981) made between conscious learning and unconscious acquisition of language. Krashen (1981) and Hammond (1988) believe that formal instruction may enhance declarative syntactical knowledge, but not the ability to use grammar appropriately. Krashen's view was supported by instances from the students' essays. That is, although they defined grammar as "sentence structure", they provided instances that refer to failure to put this knowledge in practice. Rayan, for example, expressed his confidence with memorizing a lot of grammatical rules, but could not use them in a reallife situation. He stated, "I knew that I memorized a lot of rules, this is good, but unfortunately, when I wanted to talk with a foreigner in English, I feel like I cannot make a good sentence”. Thus, declarative grammatical knowledge might be deceptive as it may not underlie actual knowledge. Furthermore, declarative knowledge may become part of its holders' belief system, informing their attitudes and behaviors. This explains comments by students about previous grammar teaching methods, "I did not like exercises at home", "we did not use the language", "the assignment was boring", "they [teachers] explained the rules in Arabic" and so on. 
The relationship between learners' beliefs and experiences on the one hand and their classroom behaviors and attitudes towards language teaching methods on the other hand was clear through the participants' experience with learning grammar in their home countries. For example, Salem expressed his concern about his inability to use what he studied at school, "I feel nervous when I am in a situation to speak with a native speaker of English because I am afraid I cannot make correct sentences which we studied at school". Marry also displayed a sense of nervousness when she answered a phone call in English, "I did not think I could speak well because when you speak, you must speak fast. This is not easy to make correct sentence. This makes me nervous".

The interpretation of the participants' declarative linguistic knowledge developed back-home is supported by Yang (1992) who found a strong correlation between learners' beliefs and anxiety. Kalaja and Barcelos (2003) also reported a correlation between learners' attitudes and their autonomous learning. The findings concerning grammar are in line with previous research that revealed how learners' beliefs influence grammar acquisition (Incecay\& Dollar, 2011). However, linguistic declarative knowledge may influence L2 learners negatively if it is wrongly established or divorced from proper application. Grammar pedagogy might not rely solely on declarative knowledge and form-based grammar instruction alone will not yield acquisition, especially in a non-native context where exposure to authentic language use is lacking. Moreover, as both beliefs and language use are situated, L2 learners are likely to develop new understanding of grammar.

\section{Grammar as an Interactional Tool}

Interestingly, grammar was viewed by the same students as an important tool for meaning. John said, "it helps us understand what others say... in the same time, we feel like people can understand us". This view to grammar advocates a shift from the traditional to the interactional perception of the notion which Francis (1954) conceptualize as Grammar 1, "the set of formal patterns in which the words of a language are arranged in order to convey larger meanings" (p. 300). In response to the questions, "why are you taking the language course?" and "how good you want your English to be?", the respondents unanimously confirmed that they were taking the course to "improve their English" and that "they wanted their English to be "perfect" like a native English speaker".

Apparently, the participants have developed this communicative notion of grammar in Canada after being exposed to the language in its natural context. Grammar in this context is a use, a need, and an attempt to adjust to the public life in a native language context. Young articulated his interest in learning grammar to use the language, "I found it interesting to learn grammar to be able to speak and write, but not to memorize". The participants now have debunked the old notion of the syntactical grammar which they had developed back home. They started to adopt the interactional aspects of language. This view was also observed from the comparisons the participants made between their back-home learning experience and the Canadian-based experience with English. Adam said, "the experience with English [back home] was not helpful". Cheng also indicated that "the focus was on grammar". Rayan expressed dissatisfaction with "some terrible lack of conversation... at that time we could not communicate, but now, we do... Grammar helps to speak and write". Marry posited, "we did not use English outside classroom". Such expressions suggest that the participants start to realize the dichotomy Chomsky (1986) proposed for linguistic knowledge between competence (the abstract knowledge of grammar) and performance (the actual application of this knowledge in the event of language use, speaking and writing). The student's statement cited above, "it helps us understand what others say" is suggestive. It indicates that grammar has come to focus on speech inherent in interactional grammar as people's exchanges are operated in the spoken form of the language.

This view of grammar also relates to the definition Francis (1954) referred to as Grammar 3 "linguistic etiquette" (spoken grammar that does not necessarily conform to written grammar). The findings also relate to Krashen's view of grammar $(1981,1982)$ that grammar is acquired through exposure and that formal instruction to the component enhances declarative knowledge, yet not acquisition. The following quotations support the claim, "some terrible lack of conversation", "the use of English was terrible" and "we did not use English outside the classroom". All these assertions are conducive to a communicative take to grammar teaching. Although the findings correspond with some related studies (Incecay \& Dollar, 2011) in which the respondents were in favor of learning grammar communicatively, Male (2011), reported that learners preferred formal presentation of grammar structures. The participants in Male's study "viewed knowledge of grammar to play an important role in writing, but has no significant role in speaking" (Male, 2011, p. 58).

They "tended to dislike self-discovery learning technique" (p. 67). 


\section{Grammar as a Rhetorical Tool}

In response to the question "what is grammar?", a third view emerged, namely one in which the participants perceived the notion with reference to writing, grammar is a rhetorical tool. This new meaning charted from a diversity of comments gathered from the interview "grammar makes writing understandable "and mainly from the evaluation of essays written by the students. The students were writing an essay about "chemical experiments". The following caption charted from a conversation that took place in a discussion session with Adam about his essays:

Moderator: what do we need to write an essay?

Adam: an introduction, a body, and a conclusion.

Moderator: what do you include in the introduction?

Adam: the main points in the essay, the road map, the argument.

Prior to the discussion, I observed that the student had written the two sentences: "chemicals can be a poison" and "they can burn the skin". He also provided similar paragraphs in the discussion and conclusion sections. The caption above and the observations I gained from evaluating the student's essay seemed to suggest that the student provided responses in consonance with the stylistic conventions of essay writing, which he and the other participants construed as part of their grammatical knowledge. Marry was also able to identify the rhetorical function of the topic sentence in the introduction section, expounding that such a sentence serves to "hook the reader as you introduce and attract him to your essay". The students' understanding of grammar in this section aligns with Hartwell's (1985) stylistic grammar, "grammatical terms used in the interest of teaching prose style" (p. 110). Ostensibly, the participants have come to adopt this notion in Canada. That is, as university students (enrolled in disciplines such marketing, computer sciences, engineering), doing assignments beyond the sentence level (paragraphs, essays, reports, etc.), they seemed to upgrade their grammatical knowledge in accord with the rhetorical conventions determined by the discourse community they belong to now. Technical writing (hence stylistic grammar) at the discourse level is now a socio-cultural imperative of the discourse community and a requirement by the discipline of which the participants have come to be members. While stressing the importance of stylistic grammar and technical writing conventions, the participants highlighted the importance of accurate use of grammar.

While Salem asserted that "grammar makes writing understandable". Marry explained, "the professor struggles to understand it [when we make grammar mistakes]". The implication of such instances is that the learners seem to believe that grammar mistakes are likely to reveal and induce more concern and confusion in writing rather than in speaking. The participants, furthermore, gave explications to such understanding. Ali, for instance, indicated that "grammatical mistakes are more serious in writing because they are corrected" which is not the case in speaking. Linking grammar to writing is suggestive through which accuracy and fluency are indispensable. They go hand in hand and none has primacy over the other. Thus, "the fact that the main objective of learning a language is to use it as a means of communication makes grammar essential" (Male, 2011, p. 59). Along the same line, Zhang (2009) argued that grammar teaching is important in the L2 classroom because "grammatical competence is one of communicative competence." (p. 184).The participants seem to adopt a formal-interactional approach to grammar; they agree with Krashen's (1981) communicative take to grammar (hence the role of exposure to grammar instruction), yet disagree with him on debunking the role of instruction and divorcing form from function.

\section{Versatility of Grammar}

Grammar "is everything"; this is how the participants, at a certain level in the interview, viewed grammar as a holistic account. Although this response might look vague, it suggests that the participants have expanded their construal to grammar to cover all levels of linguistic representation. Cheng emphasized that "without grammar, nothing can be right. Is helpful for conversation, writing, reading, and listening. So, it is everywhere." Ali also believed that grammar can "join not only words, but also thoughts, messages, and feelings. You can write to or speak with people and they reply back to you with understanding and friendship". The fact that they defined grammar as a rhetorical tool even suggests that grammar can be above the linguistic level. That is, they related grammar to the discourse organization, hence to language use.

As such, for the participants, grammar has come to jacket non-linguistic realizations, including pragmatics and socio-cultural conventions informing and underpinning grammar functionality. 
Supposedly, this is because the participants have come to identify grammar in terms of language use. Language use is more comprehensive than language. Thus, the grammatical organization encompasses the linguistic organization, the discourse organization and the socio-cultural organization. Grammar pedagogy is entrenched in all these aspects because "grammar is not only polysemous, but also greatly misunderstood or misinterpreted ... it can be "the whole system of language" (Pelosi,1973, pp., 229- 230).

Such view to grammar as "everything" reflects the participants' attempt to adapt into multiple discourse communities in Canada. The participants as sojourners, living in an English-speaking community and studying at an English-medium university have to communicate with this network of communities, where the means of communication is a language different from their L1. The view to grammar knowledge (as combining competence and performance) presupposes an interaction of both exposure and formal instruction. It could have followed from the fact that the participants are non-native speakers, thus, cannot divorce grammar instruction from language use. The emerging themes and the general findings concerning the question, "what is grammar?" are in partial agreement (or disagreement) with those of Krashen's (1981) and other opponents of formal instruction to grammar. That is, while the participants stress the role of exposure, they also stress that exposure alone will not suffice for grammar gains to occur for L2 learners; that exposure and grammar instruction cannot be divorced.

\section{Research question 2: “What are the L2 learners' perceptions about the importance of learning grammar?"}

"Why should we teach grammar?" is a question that relates to the discussion above where I explored the question, "what is grammar?" because the participants seemed to define grammar regarding the importance of learning it. In response to the question why is grammar important?, the participants stressed the importance of grammar to language in general. They thought it was important for speaking and comprehension as Salem stated, "it helps us understand what others say". Grammar is important for writing as "it makes writing understandable", John said. They construed grammar as equal to language, "it is everything".

The various accounts the students suggested above emphasize the following. First, the importance of grammar and grammar teaching to language comprehension and production. Norris and Ortega (2000) posit that grammar teaching is likely to lead to acquisition and that such a custom (Burgess\& Hetherington, 2002) is expected, accepted, and esteemed by both learners and teachers. Second, the context of language use determines the view to the status of grammar. For example, when the students think of the role of grammar as a means of communication with the Canadian community, it is rather the spoken rules they are concerned with; grammar is interactional. However, as university students, it is rather the technical writing that matters; grammar is "a rhetorical tool". As to this, the findings are in agreement with previous studies (Levine, 2003; Wach, 2011; Incecay \& Dollar, 2011) that stress importance of L2 use in the L2 language classroom and reported a strong correlation between the students view to grammar and the discourse context.

\section{Research question 3: "What teaching and learning strategies do L2 learners advocate be employed to optimally promote their learning experience with grammar and L2?}

The importance of this section of results and discussion rests on its significance to explore optimal learning strategies and teaching practices that can be assumed. The findings of the study showed that the participants emphasized various pedagogical guidelines and practices that could contribute to their learning.

\section{L1influence on L2 Grammar Learning}

Thinking back of English teaching in their home countries, all the participants indicated that they had negative attitudes towards the methods and practices through which they were introduced to English in general and to grammar in particular. As quoted above, Ali explained that English was taught "like any other subject" such as history or geography" using L1. Salem also commented, "they [teachers] explained the rules in Arabic". Moreover, Young regretted that they did not use English". The students were disappointed with these strategies as they "used to memorize the rules [which were, basically, explained in the L1], for the exam". These practices, according to one student, made the grammar class "boring". Added to this, the teachers were like the students "non-natives of English". Apparently, these attitudes highlight a negative affect about L1 use in the L2 classroom and is related to the ongoing debate about L1 use in L2 context within the frame of SLA acquisition. The use of L1 in the L2 classroom has long been debated and pedagogical grammar endured more heated controversy enriched in the exposure to language and the instruction of grammar dualism; hence the pro-L1-use and anti-L1use in the L2 class. 
Proponents of L1 use argue that L2 learners may transfer their L1 knowledge into learning the L2 grammar. Opponents of L1 use argue that exposure to L2 suffices the learning of its grammar, therefore, discredited grammar teaching, leading the L1 use in the L2 class to impede L2 use and the acquisition of its grammar (Richards \& Rodgers, 2001). The findings seem to contribute to the argument of L1 use in the L2 class. The findings in this regard are in discord with those of Kim and Petraki (2009), whose Korean participants viewed their L1 as having a scaffolding role in English language classes and a supportive key role in grammar explanations. Similarly, Wach (2011) reported on Polish L2 learners of English who preferred using L1 to using L2 (by their teachers) in ESL classes to explain grammar rules.

\section{Need of L2 Use in L2}

The participants gave a rationale for their position against the use of L1 in English grammar teaching, while arguing in favor of the use of L2 in such a context. One participant affirmed "lack of conversation"; another agreed that, "we did not use English"; a third asserted that "we were not practicing English" which made grammar learning "boring" and "difficult". This participant added that because the teachers explained the rules in L1, "the experience with English was not helpful". Apparently, these comments acknowledge the centrality of using the L2 in L2 grammar pedagogy to an interactional take to grammar teaching in order to optimally carry out the process. Interestingly, the participants stressed the role the teacher plays in leading the teaching-learning mission into a success. Such a role becomes central upon considering that learners learn L2 in a non-native context which constitutes one of the major disadvantages that L2 learners can encounter. The teacher in this regard, is responsible for creating conditions and designing activities that make up the lack of exposure to language in its socio-cultural context. As to this, the participants suggested that some activities, games, discussions, role plays can be helpful to encourage students to interact in pairs and group work. As to simulate the cultural context, one of the participants added that watching in-class English videos, at-home English movies, internet chat forums are also helpful. Another student suggested that "we need native-English teachers to teach the language" to minimize L1 use and to maximize L2 use in the English classroom as this is greater and more helpful for the interaction.

\section{Significance of Exposure to L2 In L2 Context}

Recalling their back-home experience with learning English, the participants stressed the vantage of learning grammar in an English-speaking country. This emerged from the comparison they made between, on the one hand, their back-home grammar teaching context and practices and, on the other hand, the counter experience they have been through in Canada. Thus, the non-native teacher who was "explaining the rules in [L1]" has now been replaced by "a native teacher" who "explains the rules in English". The students who "did not use English inside the classroom" have come now not only to use it inside, but "to use [it] outside the school". The "no practice of English" has turned into a full practice of the language, to the extent that they wanted to join courses to "improve [their] English, or even, desire to speak the language like a native English speaker". They have come to learn the language rather than about it and to "like learning English". Thus, "The boring experience with English [which] was not helpful", has now become a joyful one.

The participants' experience with learning English in Canada could be in harmony with Krashen (1981, 1982, 1985) and other researchers interested in the communicative language approach to L2 learning (Hammond, 1988; Truscott, 1996) who advocate that L2 learners need not be taught the grammar of English as they can learn it without a teacher. For them, exposure will suffice and unconscious acquisition will take place instead of the conscious learning and the formal teaching of grammatical structures which will enhance only learners' declarative knowledge of the grammar structures (Krashen, 1982; Hammond, 1988). However, the one-size-fitsall system is never an option. Krashen's view to grammar and its teaching has many opponents (Chaudron, 1988; Larsen-freeman, 2003; Ammar \& Spada, 2006). The participants seem to negotiate the position; they disagree with Krashen in debunking grammar and they stressed the role of its formal instruction in its learning. But they agree with Krashen about the importance of exposure in learning this aspect of language, especially in its native context. In other words, the participants supported a modified version of Krashen's communicative-input approach to language teaching as to be balanced, incorporating teaching and exposure, and integrating explicitimplicit teaching modes to grammar.

\section{Balance Between Explicit and Implicit Instruction of Grammar}

The participants preferred an integrative approach to grammar, that is, a communicative approach that acknowledges the role of formal instruction. 
Young elaborated that he liked the teacher to "explain the rules in English... give the students a chance to hear English not our language". Ali also recommended the teacher to "give examples..., practice the rules,... and give them feedback". These comments are connected to an explicit method to grammar teaching. They also mentioned that they like to learn grammar collaboratively. Salem recommended if they could "learn grammar in groups because it encourages us to exchange learning, feel safe, and gives meaning to grammar". Cheng also liked if she learnt grammar "from grammar books,... conversation..., and watching English movies". Talking about their back-home experience, they expressed negative attitudes about the teaching methods used there. They asserted that there was a "lack of conversation", that they "did not use English", and that they "were not practicing English" which made grammar learning "boring" and "difficult". Thus, "The experience with English was not helpful". Such comments map to an interactional take to grammar pedagogy.

The effectiveness of a method to grammar teaching is an utter controversy. Proponents of implicit teaching (Krashen, 1982; Truscott, 1996) argue that only simple rules are learnable even when the input is difficult. Hence, "implicit processing of material has advantage over explicit processing" (Krashen, 1982, p. 223) and "rule instruction can affect learning negatively". Conversely, other researchers (Schmidt, 1990; Harley, 1993; Spada \& Lightbow, 1993; Norris \& Ortega, 2000) argue in favor of form-focused and explicit teaching. This line of thought was also supported by empirical research. Norris and Ortega (2000) overviewed the findings of 49 studies conducted on the effectiveness of L2 teaching methods and found "that explicit teaching methods are more effective than implicit ones; and that form-focusing methods are remarkably useful in presenting the grammar to the L2er" (158). This was also supported by exploration on learners' beliefs. Male (2011) reported that the majority of participants in his study favored explicit to implicit teaching to grammar. The findings as for an explicit or implicit grammar teaching mode reflect the controversy on this issue and call for a mediation, balancing implicitness and explicitness takes.

\section{Importance of Integrating Content-Based and Task-Based Teaching on Grammar Learning}

In consonance with their integrative take on grammar teaching, the participants appear to be in favor of combining both a task-based and a content-based teaching approach to grammar. The former is form-focused, the latter is interactional. To reiterate a previous discussion, in the interview, the participants showed reasonable knowledge of the essay writing conventions. For example, Young explained, "the essay has three parts, an introduction, a body, and a conclusion". The participants also showed knowledge of the components of each rhetorical section. Young elaborated, "in the introduction, the main points of the essay, the road map, the argument" exist. Some were able to link the essay components to their rhetorical functions. For example, Cheng explained that, "the topic sentence is to hook the reader". Analysis of their essays showed evidence of putting their knowledge into practice by supplying sentences such as "chemicals can be a poison", "they can burn the skin" as supporting ideas for a topic sentence, and "chemistry experiments should be banned from public schools" with regard to an "argument" of an essay about "chemistry experiments". Likewise, the participants were in favor of a content-based take for grammar education. They explained that reading textbooks and articles in their area of study (computer science, engineering, and marketing) is useful for learning grammar; it enforces old knowledge and helps them to discover and learn new grammatical rules. Ali clarified that "reading different subject books, articles, magazines, and from the internet helps obtain new knowledge about grammar and how it is used".

The students' comments are conducive to two interrelated themes. First, grammar should be broadly presented through stylistic knowledge and genre knowledge as part of grammatical knowledge with relation to the taskbased take. Second, grammar structures are situated (that is, context-governed, their meanings and use being context-sensitive). Together, task-based and content-based approaches complement each other. The implication here is that grammar teaching should be contextual (discourse-based, not sentence based). The findings for this section are in agreement with those of Swain (2001) who studied L2 learners' grammar acquisition in French Immersion Programs and concluded that the use of tasks with using "content relevant materials encourages students to focus on form" (p. 145) and that language and content cannot be separated. The findings are also in line with Fotos (1994) who concluded that grammar-consciousness raising tasks promoted proficiency gains and L2 interaction. The finding, are also in line with those of Zhang (2009) who concluded that communicative competence is part and parcel of our grammatical competence.

\section{Corrective Feedback Influences Grammar Learning}

As for grammar correction, the following points emerged. In the interview, one participant, Ali affirmed that he liked "teachers to correct mistakes" because that "helps [him] to learn the grammar". 
Salem thought that feedback is "more important for writing "because correct grammar "makes writing understandable". Young also elaborated, "when I make mistakes, the teacher does not understand what I want to say". Cheng posited that the situation is different for speaking "because people don't correct you when you speak". Analyzing students' writing followed by feedback sessions suggested that the students benefitted from both prompts (implicit feedback) and recasts (explicit feedback). For example, Salem wrote "to safe children, chemistry experiments...". We simply underlined safe for the student who then supplied the correct sentence "to save children". Young clarified how the teacher's feedback helped him to "pay more attention to [his] mistakes, then worked in accordance with the teacher's feedback to fix errors". Cheng did not see the teacher's feedback as indication for "defect, but as a tool to enhance language accuracy and fluency. Ali preferred that his teacher "should not provide the corrected form of errors... but prompts to help notice and correct them". The findings also revealed that all the students favored prompts feedback over recasts because "they learn grammar" when corrected indirectly. In L2 pedagogy research, the role of error correction of L2 grammar has been controversial (Ding, 2012) which might be attributed to the communicative tendencies to language teaching. Proponents of correction (Chaudron, 1988; Harley, 1993; Larsen-Freeman, 2003: Spada \& Lightbow, 1993) argue that feedback is an event for learning. Chaudron (1988) stresses that "the use of feedback may constitute the most potent source of improving target language development" (p. 133). Conversely, opponents of feedback (Krashen, 1982; Krashen \& Terrell, 1983; Hammond, 1988; Truscott; 1998) argue that it is pointless, harmful and learning-impeding. Krashen (1982) states, "even under the best of conditions, with the most learning-oriented students, teacher corrections will not produce results that will live up to the expectations of many instructors" (p. 119). Apparently, the participants advocated a helpful role for correction. They believed that feedback is conducive to learning. This perspective agrees with Larsen-Freeman's (2003) as "an opportunity for learning to take place" (p. 126). The findings are also in line with classroom research on the role and type of correction. Ammar and Spada (2006) reported positive correlation between feedback and achievement. Their participants benefited significantly more from feedback in the form of prompts. The findings are also in line with research on students' beliefs about feedback and grammar teaching. Schulz (2001) reported strong belief of students in the positive impact of corrective feedback and grammar learning. Incecay and Dollar (2011) supported these findings and indicated that the learners in their study believed that grammar was important and that error correction was useful to learn the language.

\section{Role of Practice in Learning Grammar}

One of the questions I attempted to answer is 'what strategies do you use to improve your English?' The following points unfolded, "I read (grammar) books", "I watch English movies", and "I chat with English speakers". These suggestions seem to integrate all the receptive (reading and listening) and productive (speaking and writing) skills of language. In a non-native context where exposure to authentic L2 is rare, learning the rules of L2 and the conventions of its use constitutes a challenge for L2 learners. In this regard, TV is considered a helpful didactic tool. It comprises a key source for language learning as it provides data for comprehension.TV allows access to diverse forms and registers of language; it is a classroom-friendly teaching aid. Kiely (2005) offers several uses of TV as it can be utilized to introduce linguistic forms, language use, and social practices. Teachers can use the material watched as a topic for reflection orally and in writing to further learners' fluency and communicative gains.

The internet has a key role in L2 learning which has been well documented by research as it has established a solid ground for the use of the internet in L2 instruction that led to significant progress in the use and second language acquisition (Kasanga, 1996; Wiburg \& Butker-Pasceo, 2002; Aydin, 2009). Wiburg and Butker-Pasceo (2002) found that the using the internet motivates language use. Aydin (2009) concluded that communication with native speakers through internet-based forums enhances skills integral to second language learning skills such as discussion, persuasion, clarification, and exploration. Furthermore, using the internet enhances other strategic skills such as planning, time management and problem solving.

It becomes obvious that by answering the research questions, various views about grammar emerged from their experience with learning English. With regard to the first question, grammar, accordingly is not a static concept with rigid operationalization. Rather, it is a dynamic construct which interdependent with the learning context that a learner is exposed to. There is a reciprocal influence among several constituents that shape a learner's perspective, including but not limited to the teacher, teaching methods, learning environment, purpose of learning, and authentic settings. 
The second question implies that the utility of grammar is situated. Learners of English might consider grammar important for its role to facilitate comprehension and production of the language. They might see it as a tool of communication when they use the language as a social practice. They could see it as a rhetoric when delivering more specified discourse. The third question revealed meaningful insight on optimal pedagogy to be associated with grammar. Grammar gives its best when the teacher capitalizes the learners' prior knowledge and skills, learning needs, learning styles and preferences, and attitudes.

\section{Conclusion}

Although the study is limited by the number of its participants, it highlighted problematic issues concerning L2 grammar pedagogy. The findings suggest the role of exposure in teaching grammar. The first implication prompts that a communicative approach to grammar teaching cannot divorce the role of formal instruction to grammar. Stressing the role of exposure and formal teaching of L2 grammar, the study suggests considering a modified version of the communicative-input approach to language teaching. Due to lack of exposure to L2 in a non-native context, teachers are advised to create an exposure-like context through which they can present the L2 grammatical structures. Another in sight the study stresses is the importance of error correction as an opportunity for learning. The findings suggest adopting an inclusive notion to grammar; one that covers phonology, morphology, syntax, pragmatics, stylistics, and discourse or genre conventions. The implication here is that, an adequate model to grammar teaching should take into account all levels of linguistic and paralinguistic representation; optimal grammar pedagogy should be discourse-based. The study also stresses balancing learnercentered instruction and the importance of learner's beliefs to second language teaching planning. Investigating learners' beliefs, the study underlies the integrity of self-reported data to educational research.

\section{References}

Ammar, A., \& Spada, N. (2006). One size fits all? Recasts, Prompts, and L2 Learning. SSLA, 28, 543-574.

Aydin, S. (2007). The uses of the internet in ESL learning: Problems, advantages, and disadvantages. Humanizing Language Teaching. Year 9. Issue 1. Retrieved from

http://www.hltmag.co.uk/jan07/sart02.htm

Bernat, E. (2008). Beyond beliefs: Psycho-cognitive, sociocultural and emergent ecological approaches to learner perceptions in foreign language acquisition. Asian EFL Journal, 10(3), 8-28.

Bresnan, J. (1982). The mental representations of grammatical relations. Cambridge: MIT Press.

Burgess, J., \& Etherington, S. (2002). Focus on grammatical form: Explicit or implicit? System, 30, 433-458.

Chomsky, N. (1986). Barriers. Cambridge: MIT Press.

Clahsen, H., \&Muysken, P. (1986). The availability of universal grammar to adult and child learners: a study of the acquisition of German word order. Second Language Research 2, 93-119.

Chaudron, C. (1988). Second language classrooms: Research on teaching and learning. Cambridge: Cambridge University Press.

Creswell, J. W., \& Plano Clark, V. L. (2011). Designing and conducting mixed methods research (2nd ed.). Thousand Oaks, CA: Sage.

Davis, A. (2003). Teachers' and students' beliefs regarding aspects of language learning. Evaluation \& Research in Education, 17 (4), 207-222.

Ding, T. (2012). The Comparative effectiveness of recasts and prompts in second language classrooms. Journal of Cambridge Studies, 7(2), 83-97.

Ellis, R. (2002). The place of grammar instruction in the second/foreign language curriculum. In E. Hinkel\& S. Fotos (Eds.), New perspectives on grammar teaching in second language classrooms (pp. 17-34). London: Lawrence Erlbaum Associates.

Ellis, R. (2006). Current issues in the teaching of grammar: An SLA perspective.TESOL Quarterly, 40(1), 83-107.

Fotos, S. S. (1994). Integrating grammar instruction and communicative language use through grammarconsciousness-raising tasks. TESOL Quarterly, 28(2), 323-351.

Francis, W. (1954). Revolution in grammar. Quarterly Journal of Speech, 40(3), 299-312.

Gall, M.D., Gall, J.P., \& Borg, W.R. (2007). Educational research: An introduction (8th Eds.). Boston, New York and San Francisco: Pearson Education Inc.

Halliday, M.A.K. (1973). Explorations in the functions of language. London: Edward Arnold. 
Hammond, R. (1988). Accuracy versus communicative competency: The acquisition of grammar in the second language classroom. Hispania, 71, 408-417.

Harley, B. (1993). Instructional strategies and SLA in early French immersion. Studies in Second Language Acquisition, 15, 245-259.

Harris, K. R., Santangelo, T. \& Graham, S. (2010). Metacognition and strategies instruction in writing. In H.S. Waters \& W. Schneider (Eds.), Metacognition, strategy use, and instruction (pp. 226-256). New York, NY: Guilford Press.

Hartwell, P. (1985). Grammar, grammars, and the teaching of grammar. College English, 47(2), 105-127.

Hawkins, R. (2002). The theoretical significance of Universal Grammar in second language Acquisition. Second Language Research, 17(4), 345-367.

Hudson, R. (1998). Is grammar teachable? English 4, 11(2), 11-14.

Incecay, V., \& Dollar, Y. K. (2011). Foreign language learners' beliefs about grammar instruction and error correction. Procedia-Social and Behavioral Sciences, 15, 3394-3398.

Kasanga, L. A. (1996). Peer interaction and second language learning. Canadian Modern Language Review, 52 (4), 611-639.

Kalaja, P., \&Barcelos, A. M. F. (2003). New research approaches. Dordrecht: Kluwer.

Kiely, R. (2005). The role of television and television literacy in language teaching and learning. Retrieved from http://www.developingteachers.com/articles_tchtraining/tv1_richard.htm

Kim, Y., \&Petraki, E. (2009). Students' and teachers' use of, and attitudes to, L1 in the EFL classroom. Asian EFL Journal, 11(4), 58-89.

Krashen, S. D. (1981). Second language acquisition and second language learning. Oxford: Oxford University Press.

Krashen, S. D. (1982). Principles and practice in second language acquisition. Oxford: Pergamum.

Krashen, S. D. (1985). The input hypothesis: Issues and implications. London: Longman.

Krashen, S., \& Terrell, T. (1983). The natural approach. Hayward, California: Hayward Press.

Larsen-Freeman, D. (2003). Teaching language: From grammar to grammaring. Boston: Thomson \&Heinle.

Larsen-Freeman, D. (2009). Teaching language: From grammar to grammaring. Beijing: Foreign Language Teaching and Research Press.

Levine, G. S. (2003). Student and instructor beliefs and attitudes about TL use, first language use, and anxiety: Report of a questionnaire study. The Modern Language Journal, 87(3), 343-364.

Loewen, S., Li, S., Fei, F., Thompson, A., Nakatsukasa, K., Ahn, S., \& Chen, X. (2009). Second language learners' beliefs about grammar instruction and error correction. The Modern Language Journal, 93(1), 91-104.

Male, H. (2011). Students' view on grammar teaching. Journal of English Teaching, 1(1), 57-69.

Mori, Y. (1999). Epistemological beliefs and language learning beliefs: What do language learners believe about their learning? Language Learning, 49, 377-415.

Norris, J., \& Ortega, L. (2000). Effectiveness of L2 instruction: A research synthesis and quantitative metaanalysis. Language Learning, 50(3), 417-528.

Nunan, D. (1988). The learner-centered curriculum: A study in second languageteaching. In M. Long and J. Richards (eds). Cambridge: CUP.

Pelosi, A. (1973). What is "Grammar”? The Modern Language Journal, 57(7), 329-335.

Richards, J., \& Rodgers, T. (2001). Approaches and methods in language teaching. Cambridge: Cambridge University Press.

Saldana, J. (2009). The coding manual for qualitative research. London: Sage.

Schachter, J. (1988). Second language acquisition and its relationship to Universal Grammar. Applied Linguistics, 9, 219-235.

Schmidt, R. (1990). The role of conscious construction in second language learning. Applied Linguistics, 11, 129158.

Schulz, R. (2001). Cultural differences in student and teacher perceptions concerning the role of grammar instruction and corrective feedback: USA-Colombia. Modern Language Journal, 85, 244-258.

Spada, N, \&Lightbow, B. (1993). Instruction and development of questions in L2 classrooms. Studies in Second Language Acquisition, 15, 205-224. 
Swain, M. (2001). Integrating language and content teaching through collaborative tasks. Canadian Modern Language Review/La Revue canadienne des languesvivantes, 58(1), 44-63.

Thornbury, S. (1999). How to teach grammar. London: Longman.

Tomlison, B. (2005). English as a foreign language: Matching procedures to the context of learning. In E. Hinkel (Ed.), Handbook of research in second language teaching and learning (pp. 137-153). New Jersey: Lawrence Erlbaum Associates Publishers.

Truscott, J. (1996). Review article: The case against grammar correction in L2 writing classes. Language Learning 46, 327-369.

Wach, A. (2011). Grammar instruction in ELT: Insights from the classroom. In M. Pawlak (Ed.), In extending the boundaries of research on second language learning and teaching (pp. 29-39). Berlin: Springer.

Westney, P. (1994). 4 Rules and pedagogical grammar. In T. Odlin (ed.), Perspectives on pedagogical grammar (pp. 72-99). Cambridge: Cambridge University Press.

Wiburg, K., \& Butler-Pascoe, M.E. (2002). Technology and teaching English language learners. New Jersey: Prentice Hall, Inc.

Yang, N. D. (1992). Second language learner's beliefs about language learning and their use of learning strategies: A study of college students of English in Taiwan. (Unpublished doctoral dissertation) University of Texas, Austin.

Zhang, J. (2009). Necessity of grammar teaching. Journal of International Education Studies, 2(2), 184-187. 